\title{
Formation of two types of cysts by a mixotrophic dinoflagellate, Pfiesteria piscicida
}

\author{
J. T. Anderson ${ }^{1,2, *}$, D. K. Stoecker ${ }^{1}$, R. R. Hood $^{1}$ \\ ${ }^{1}$ University of Maryland Center for Environmental Science, Horn Point Laboratory, PO Box 775, Cambridge, Maryland 21613, USA \\ ${ }^{2}$ Present address: Skidaway Institute of Oceanography, 10 Ocean Science Circle, Savannah, Georgia 31411, USA
}

\begin{abstract}
Despite the widespread occurrence of mixotrophic dinoflagellates, most research on cyst formation in dinoflagellates has focused on phototrophic organisms or on factors affecting phototrophic growth (i.e. light intensity and nutrient supply). Presumably, factors that stimulate cyst formation in mixotrophic organisms would be combinations of those factors that affect phototrophic and phagotrophic growth (such as limiting light intensity and limiting prey concentrations). The toxic dinoflagellate Pfiesteria piscicida is an interesting test case because it has a complex life history and is considered mixotrophic. Recently, a form of $P$. piscicida has been described that does not have the ability to produce toxins (termed 'non-inducible'). The objectives of this study were to identify which life stages are likely to be present in a mixotrophic culture of 'non-inducible' P. piscicida and to determine the morphological differences based on fluorescent stain uptake. Also, we examined which combinations of adverse environmental factors (low light intensity and low prey concentrations) affect life stage transformations. In this culture, we observed 3 distinct life stages (a zoospore stage, and 2 cysts). One of the cysts (termed Cyst A) has a thick cell wall and appears to form from actively feeding zoospores regardless of light intensity. The second type of cyst (Cyst B) has a much thinner cell wall and only forms from recently fed zoospores maintained in complete darkness. During the experiment, encystment rates to either cyst were low, suggesting that encystment will not dramatically affect bloom dynamics on small timescales.
\end{abstract}

KEY WORDS: Pfiesteria piscicida · Harmful algal blooms · Kleptochloroplastidy · Mixotrophy $\cdot$ Life history transformations $\cdot$ Resting stages

Resale or republication not permitted without written consent of the publisher

\section{INTRODUCTION}

The formation of resting stages (or cysts) is common in many plankton species. These life stages can affect the spatial and temporal distribution of populations as well as affect ecosystem dynamics. In certain seasons, resting stages can contribute a considerable portion of particulate organic flux to the benthos and may play a major role in bloom dissipation (Heiskanen 1993). Cysts can also function as a defense against a variety of adverse environmental conditions as well as predators (Tyler et al. 1982, Blanco 1995, Rengefors et al. 1998). In certain cases, resistant sexual cysts can function as a means of genetic mixing and dispersal among subpopulations (Pfiester \& Anderson 1987). Understanding the mechanisms and triggers of encystment is impor-

*Email: anderson@skio.peachnet.edu tant to understanding the distribution and persistence of algal blooms.

Life stage transformations in dinoflagellates can be induced by a variety of environmental factors (Anderson et al. 1985, Sanderson \& Frost 1996). For example, encystment can be stimulated in unfavorable conditions, such as limiting ambient or internal nutrient concentrations (Anderson et al. 1985, Blackburn et al. 1989, Doucette et al. 1989, Jensen \& Moestrup 1997). In contrast, some dinoflagellates may undergo a sexual cycle (i.e. form flagellated gametes) under apparently nutrient-replete, 'optimal' conditions (Burkholder \& Glasgow 1997a, Kremp \& Heiskanen 1999). Also, some transformations may not be directly related to nutrition, but induced by seasonal changes (i.e. daylength; Hardeland 1994, Sgrosso et al. 2001). Transformations 
can also occur with changes in irradiance or decreases in temperature (Anderson et al. 1985, Hardeland 1994, Sgrosso et al. 2001), or decreases in dissolved oxygen (Pfiester \& Anderson 1987, Sanderson \& Frost 1996).

Despite the fact that dinoflagellates are considered a diverse taxonomic group with representative phototrophs, phagotrophs and mixotrophs (which have the ability to combine both phototrophy and phagotrophy), the above-mentioned research represents only a small subset of these diverse nutritional strategies. The majority of species examined are considered purely phototrophic organisms (e.g. Alexandrium tamarense, Doucette et al. 1989; Gyrodinium catenatum, Blackburn et al. 1989), or potential mixotrophic organisms that were either grown exclusively as phototrophs, or did not have their mixotrophic state reported (e.g. Gyrodinium uncatenum, Anderson et al. 1985; Alexandrium ostenfeldii, Jensen \& Moestrup 1997, Stoecker 1999). Just as ambient nutrient concentrations can affect transformation rates in phototrophic organisms, prey concentrations in some cases affect transformation rates in phagotrophic organisms (Burkholder \& Glasgow 1997a). Similarly, transformations in mixotrophic organisms may be stimulated by combinations of factors that affect phagotrophy and phototrophy.

The potentially toxic mixotrophic dinoflagellate Pfiesteria piscicida can have a complex life history with the ability to transform among an array of flagellated, amoeboid and encysted stages. Research on life stage transformations of $P$. piscicida (Burkholder et al. 1995, Burkholder \& Glasgow 1997a) has focused on toxic outbreaks and a phagotrophic context. Recently, Burkholder et al. (2001) revised the terminology used to describe the toxin-producing ability of $P$. piscicida. The revised terminology separates Pfiesteria species into 'actively toxic' (TOX-A), 'potentially toxic' (TOXB) and 'non-inducible' (NON-IND) functional types, based on their response to exposure to fish (Burkholder et al. 2001). Differences among these functional types are also manifested in their response to nutrients and microalgal prey (Burkholder et al. 2001) as well as their resistance to predation (Stoecker et al. 2000).

Life stage transformations in the TOX-A and TOX-B forms are strongly influenced by biological and physical factors. The detection of unknown substance(s) secreted by finfish stimulates toxic zoospores (TZs) to emerge from benthic cysts or amoeboid stages (Burkholder et al. 1995). The toxin(s) produced by the TZs causes bleeding sores and sloughs fragments of fish epidermis and tissue (Steidinger et al. 1996). During this time, the zoospores feed on the fish fragments and may continue to reproduce asexually, or form amoeba and temporary cysts, or may undergo a sexual cycle (Burkholder \& Glasgow 1997b). Environmental factors such as temperature, salinity, and nutrient availability can affect how readily populations respond to finfish stimuli and therefore can affect bloom dynamics (Burkholder \& Glasgow 1997b).

In contrast to the TOX-A and TOX-B forms of Pfiesteria piscicida, little is known about the 'non-inducible' forms. However, NON-IND forms of Pfiesteria can comprise $\sim 40 \%$ of all Pfiesteria forms found in nature (Burkholder et al. 2001). The non-inducible forms may be ecologically important as predators and prey to other organisms (Mallin et al. 1995, Stoecker et al. 2000). For example, non-inducible forms are capable of consuming bacteria, protozoa and/or microalgae (Mallin et al. 1995, Lewitus 1999), and may also function as temporary mixotrophs (Steidinger et al. 1996, Lewitus et al. 1999). Zoospores can accumulate ingested algae in food vacuoles, digest part of the algal cell, and retain the chloroplasts. These stolen chloroplasts ('kleptochloroplasts') can maintain their photosynthetic activity for days to weeks and might be a survival mechanism during prey-depleted conditions (Lewitus et al. 1999, Stoecker 1999).

However, Pfiesteria piscicida, like other kleptoplastidic mixotrophs, does not appear to have the ability to replicate stolen chloroplasts. Periodic replenishment of chloroplasts from algal prey is necessary for mixotrophy to persist. Limiting concentrations or total absence of algal prey may reduce the growth rates of these organisms (Skovgaard 1998). Similarly, light intensity can affect the functioning and retention time of captured chloroplasts. Exposure to limiting prey concentrations or limiting irradiance may stimulate transformation to resting stages.

Understanding the interrelationship between mixotrophy and life history transformations in Pfiesteria piscicida is vital to understanding its ecological role and spatial distribution. If differences exist among the TOX-A, TOX-B and NON-IND forms with respect to toxin production, and these differences are physiological and/or genetic in origin, then presumably other differences may also exist (e.g. with respect to life stage transformations).

The purpose of this investigation is 2-fold: (1) we determine which life stages are likely to be present in the non-inducible functional type of Pfiesteria piscicida; (2) through laboratory experiments, we examine the effect of 2 limiting factors for mixotrophs (low light intensity and low prey concentrations) on stage transformations of non-inducible $P$. piscicida.

\section{MATERIALS AND METHODS}

Cultures. The Pfiesteria piscicida culture was cloned from a Maryland strain isolated by the Florida Depart- 
ment of Environmental Protection (MDR23). Strain MDR23 has not been toxic in bioassays with fish and is thus considered NON-IND (J. M. Burkholder pers. comm.). Prior to the experiments, the P. piscicida stocks were maintained on cryptophyte prey (Storeatula major) by pulse feeding every $2 \mathrm{~d}$. All stocks and experimental treatments were kept in $250 \mathrm{ml}$ plastic tissue culture flasks (VWR brand) containing Indian River, Delaware seawater diluted to 15 PSU, GF/F-filtered, autoclaved and spiked with f/2-Si cultured medium. The stocks were placed in Percival growth chambers at $20^{\circ} \mathrm{C}$ under moderate irradiance $(\sim 80 \mu \mathrm{mol}$ photons $\mathrm{m}^{-2} \mathrm{~s}^{-1}$ ) with a 12:12 light:dark photoperiod. All life stages encountered were isolated and confirmed as $P$. piscicida using an 18S rDNA probe (University of Baltimore Institute of Human Virology; Bowers et al. 2000).

Fluorescent stains. To qualify the physiological and morphological differences between the life stages, a series of fluorescent stains was applied to samples of the stock culture. To obtain cysts to stain, pieces of microscope glass coverslips were added to the bottom of a growing culture. Newly formed cysts attached to the coverslips and these were retrieved with forceps without destroying the culture. The coverslips were placed in petri dishes, and half of the samples were fixed in $2 \%$ glutaraldehyde.

The final concentrations of fluorescent stains were based on published concentrations and modified to optimize staining of Pfiesteria piscicida. Fixed samples were stained with proflavine (Sigma, $5.0 \mu \mathrm{g} \mathrm{ml}^{-1}$ final

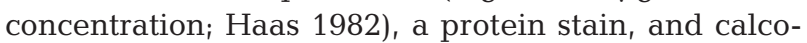
fluor (Sigma, $15 \mu \mathrm{g} \mathrm{ml}^{-1}$ final; Fritz \& Triemer 1985), a cellulose stain, to highlight structures on the cell surface. To highlight internal structures such as lipid vesicles, fixed samples were stained with Nile Red (Molecular Probes, $6.75 \mathrm{\mu g} \mathrm{ml}^{-1}$ final; Greenspan et al. 1985) for $30 \mathrm{~min}$. Unfixed samples were stained for $1 \mathrm{~h}$ with CMFDA (Molecular Probes, $4 \mu$ M final; Jochem 1999), a cytoplasm stain that fluoresces when cleaved by esterase. Other unfixed samples were split (half heatkilled, half live) and stained for 5 min with SYTOX (Molecular Probes, 6.0 $\mu \mathrm{M}$ final; Lebaron et al. 1998), a nucleic acid stain used as an exclusion stain to test cell membrane integrity.

Two additional nucleic acid stains, DAPI (Sigma, $25 \mathrm{ng} \mathrm{ml}^{-1}$ final concentration; Porter \& Feig 1980) and SYTO 13 (Molecular Probes, $100 \mathrm{nM}$ final; del Giorgio et al. 1996), were used to highlight the nucleus. From preliminary staining experiments, neither stain was able to directly penetrate either cyst wall. Therefore, zoospores were incubated with SYTO 13 for at least $1 \mathrm{~d}$ in complete darkness and monitored in $3 \mathrm{ml}$ well plates until encystment. Cysts formed from SYTO 13-stained zoospores retained fluorescence.
All stained cells were examined using a Nikon Eclipse E800 compound microscope. A blue light emission filter set and exciter (B-2E/C, excitation 465 to $495 \mathrm{~nm}$, dichromatic beam splitter $505 \mathrm{~nm}$, barrier 515 to $555 \mathrm{~nm}$ ) was used for proflavine, CMFDA, Nile Red, SYTO 13, and SYTOX stains. A green light emission filter set (G-2E/C, excitation 528 to $553 \mathrm{~nm}$, dichromatic beam splitter $565 \mathrm{~nm}$, barrier 600 to $660 \mathrm{~nm})$ was used for phycoerythrin autofluorescence. A UV emission filter set (UV-2E/C, excitation 330 to $380 \mathrm{~nm}$, diachromatic beam splitter $400 \mathrm{~nm}$, barrier 435 to $485 \mathrm{~nm}$ ) was used for DAPI and calcofluor stains.

Experimental design. The laboratory experiment was designed as a $2 \times 3$ factorial of light intensity and prey density with 3 replicates. The light intensities tested were moderate irradiance $(83 \mu \mathrm{mol}$ photons $\mathrm{m}^{-2} \mathrm{~s}^{-1}$ ) with a 12:12 $\mathrm{h}$ light:dark photoperiod and complete darkness. Algal prey densities tested were no prey (the control), 5000 cells ml $^{-1}$ (2:1 prey:Pfiesteria) and 12500 cells ml $^{-1}$ (5:1 ratio). Not all treatments could be run at the same time and were therefore divided into a light experiment and a dark experiment that started $7 \mathrm{~d}$ after the light experiment began. For both light and dark experiments, the same Pfiesteria piscicida and algal prey stocks were used. At the beginning of each experiment, stock densities were determined by epifluorescence microscopy and each flask was inoculated with 2500 zoospores $\mathrm{ml}^{-1}$ from a stock that was fed $2 \mathrm{~d}$ earlier. Prey concentrations in the $P$. piscicida stock were undetectable after $2 \mathrm{~d}$. Each flask was then exposed to a single inoculum of one of the algal prey densities and placed on its flat side. Flasks were sampled on the first and second days of the experiment, and then every other day for $13 \mathrm{~d}$. On each sampling day, aliquots were taken and fixed for epifluorescence microscopy to enumerate freeswimming life stages. Transects of the flat side of the culture flask were also conducted to enumerate cyst stages (see 'Enumeration of cells').

Enumeration of cells. Aliquots taken during the experiment were preserved with $1.25 \%$ glutaraldehyde (final concentration) and refrigerated at $4{ }^{\circ} \mathrm{C}$ for at least $1 \mathrm{~h}$. For enumeration, the samples were filtered onto $25 \mathrm{~mm}$ diameter, black polycarbonate filters with $2 \mu \mathrm{m}$ pore size (Osmonics brand). A $5 \mu \mathrm{m}$ cellulose nitrate filter (VWR brand) was used as a backing filter to ensure an even distribution of cells. Optimal sample volumes for enumeration were estimated from the treatment's previous concentration with an attempt to count at least 100 cells on a filter. Throughout the experiments, sample volumes used for enumeration ranged from $0.75 \mathrm{ml}$ to $2.0 \mathrm{ml}$. All sample volumes were diluted to $3 \mathrm{ml}$ with filtered seawater media (15 psu) to aid in the distribution of cells on the filter. 
Samples were stained with proflavine at $5.0 \mu \mathrm{g} \mathrm{ml}^{-1}$ final concentration and immediately filtered with a low vacuum. The filter was then placed on a glass slide and sealed with a small drop of immersion oil and a cover slip. For each slide, the average of 2 transects was used to calculate cell concentrations.

In addition to enumerating free-swimming stages, the flat side of each flask was examined to determine the concentration of benthic life stages. Counts were determined from the average of 3 lengthwise transects (2 approximately $1.5 \mathrm{~cm}$ from each side, 1 in the center) using a Zeiss Axiovert 35 inverted microscope under phase contrast lighting with a $20 \times$ objective. Using this method, an area of $2025 \mathrm{~mm}^{2}$ (20\% of the total area of the flat side) was examined for each flask. Before each transect, the flask was gently inverted 3 times to resuspend unattached cells. From preliminary experiments, it was determined that cysts would remain attached to the flat side of the flask even after moderate shaking. Furthermore, no cysts were observed attached to the upright sides of the flask.

To convert the transect counts into concentrations, a standard curve was established for the flat side of the flask. Five known concentrations of $15 \mu \mathrm{m}$ latex beads were added to clean tissue culture flasks and allowed to settle on the flat side. For each bead concentration, 10 transects were completed. In light of the observation that cysts remain attached to the flat side of the flask and under the assumption that the distribution of both types of cysts was similar to the distribution of latex beads, the transect counts could be transformed into cells $\mathrm{mm}^{-2}$ and then into cells $\mathrm{ml}^{-1}$.

\section{RESULTS}

\section{Stages present in the non-inducible strain}

A small subset of the life stages described in Burkholder \& Glasgow (1997a) were observed in cultures (Fig. 1). These stages include zoospores and 2 types of cysts. No Pfiesteria amoeboid stages were observed. In all experimental treatments, the zoospores were the most dominant life stage. The 2 observed cysts (Cyst A and Cyst B) were less abundant, but in older, fed cultures ( $>20$ d) they accumulated to significant concentrations.

The flagellated zoospore stage encountered in the non-inducible strain was between 7 and $18 \mu \mathrm{m}$ diameter, depending on feeding history. Under normal light, zoospores appeared colorless or slightly brown. Recently fed zoospores contained distinct food vacuoles that fluoresced orange-red from the phycoerythrincontaining prey. The thecal plates stained blue-white with the cellulose stain calcofluor (Fig. 2). The green protein stain, proflavine, stained both the cell surface and internally near the nucleus (Fig. 2). Live zoospores stained bright green when incubated with CMFDA, suggesting intracellular activity. The nucleic acid stains DAPI and SYTO 13 easily permeated the zoospores, revealing a large, condensed nucleus in the episome (Fig. 2). Nile Red, the lipophilic stain, brightly stained a cluster of yellow-orange vesicles located in the hyposome and a ring of smaller vesicles surrounding the nucleus in the episome.

Cyst A was round or less frequently ovoid and has a thick cell wall that appears reddish under phase contrast. During the experiment, Cyst A ranged from 10 to $20 \mu \mathrm{m}$ diameter. The cyst wall does not appear to stain with proflavine, but stains with calcofluor (Fig. 2) suggesting the cell wall is composed of cellulose and not protein. Furthermore, proflavine did not penetrate the cyst. SYTOX did not stain the cyst even after attempts to permeate the membrane with $5 \%$ sodium dodecyl sulfate (SDS) and 10\% $\mathrm{HCl}$. However, nuclei of heat-killed Cyst A cells stained with SYTOX. These results indicate that Cyst A has an intact cell membrane. In a few cases, the cyst contains an orange-red fluorescent vesicle, possibly a retained food vacuole. The esterase activity stain, CMFDA, did not stain the cyst's cytoplasm, but appeared to stain the orange-red vesicle slightly (Fig. 2). Cyst A was resistant to direct

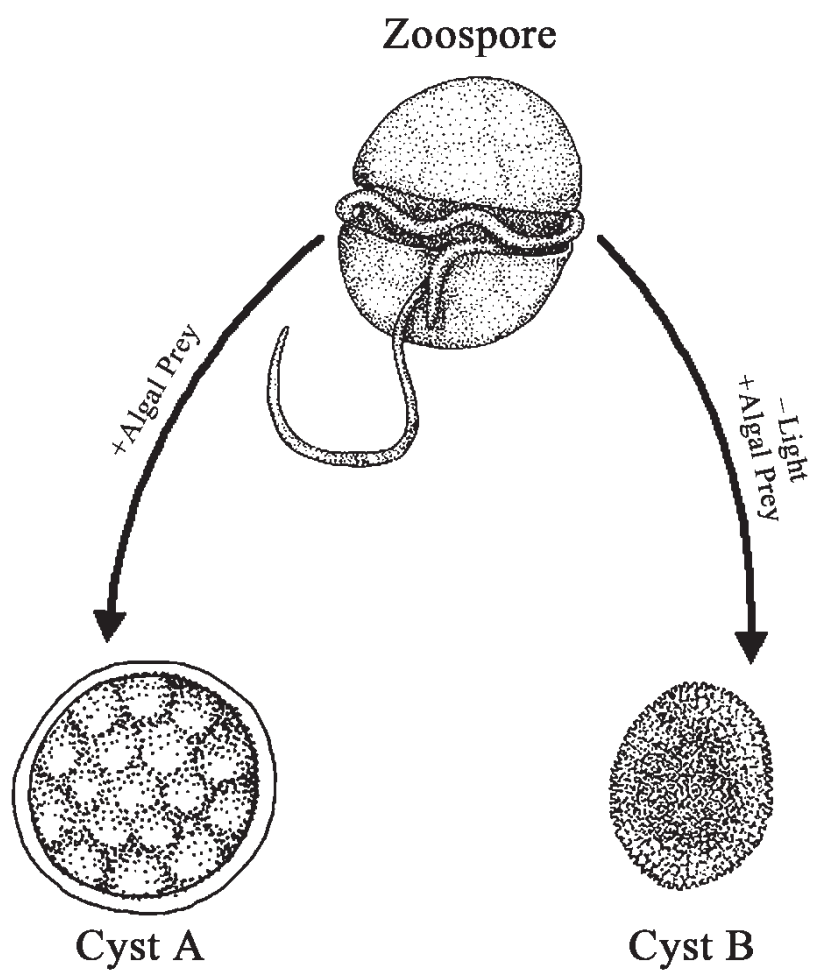

Fig. 1. Pfiesteria piscicida. Life history of the non-inducible strain as inferred from laboratory experiments. Drawing by Deborah Kennedy 


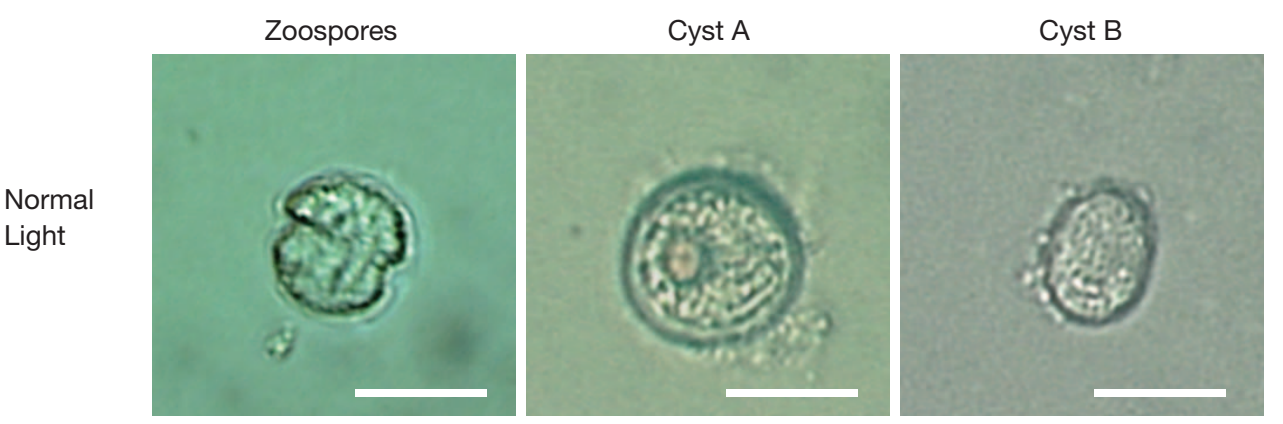

CMFDA
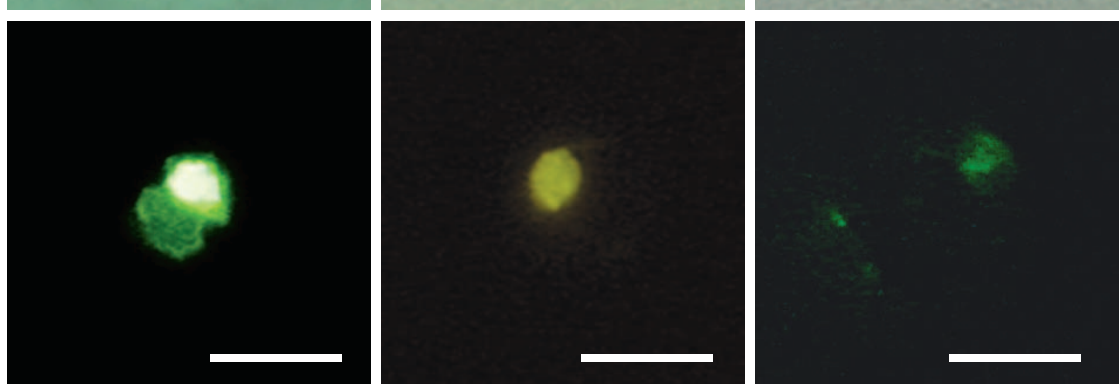

SYTO 13
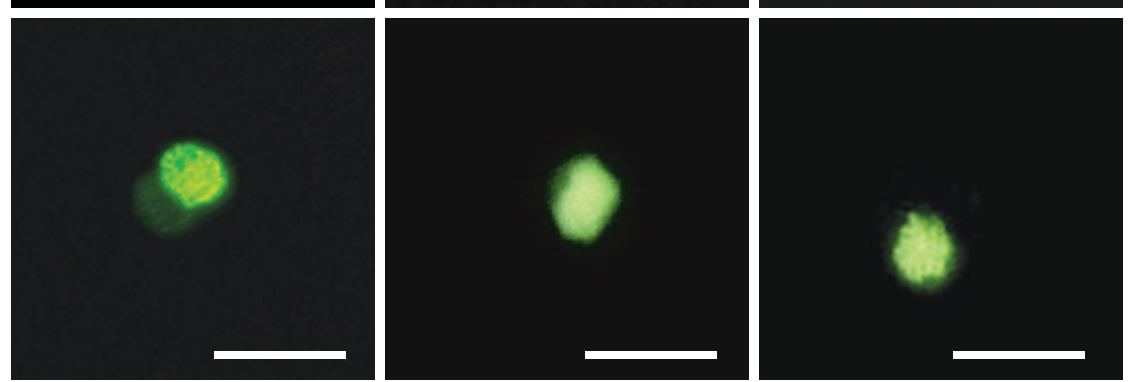

Nile Red
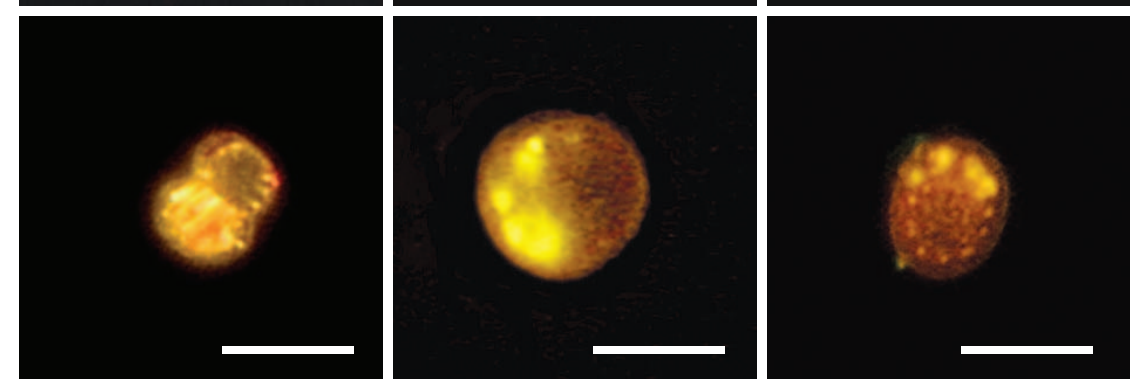

Fig. 2. Pfiesteria piscicida. Differential morphology and staining of the life stages. Note the differences in CMFDA staining between the zoospore stage and both cysts. Images of SYTO 13-stained cysts were derived from stained zoospore precursors. Scale bars $=10 \mu \mathrm{m}$ length
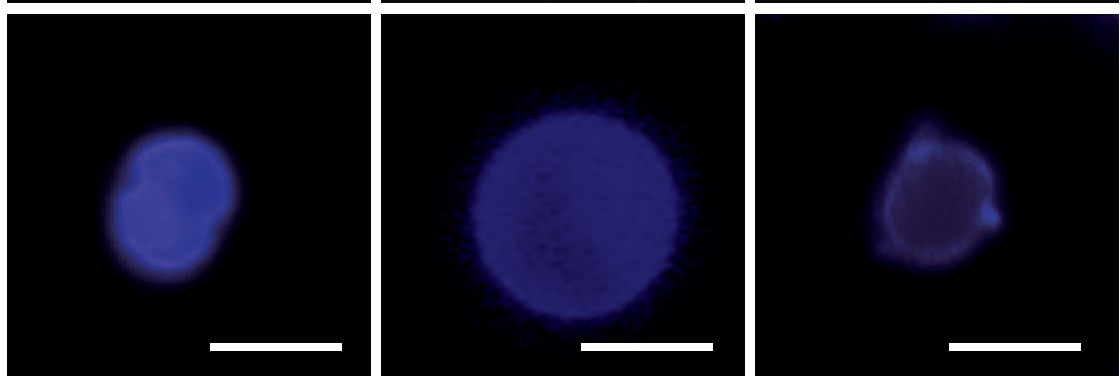

Calcofluor
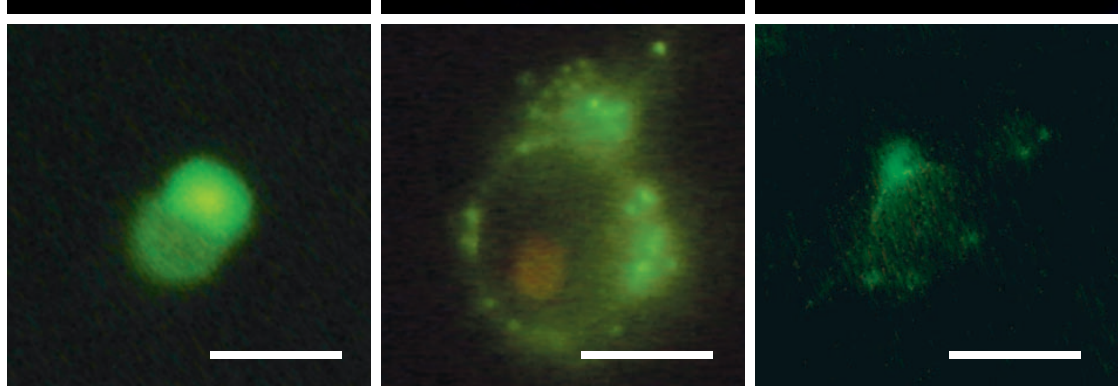
staining attempts with the nucleic acid stains DAPI and SYTO 13. However, cysts derived from recently stained zoospores retained fluorescence. Stained nuclear material of Cyst A was condensed and looked similar to stained zoospore nuclei (Fig. 2). The lipophilic stain (Nile Red) easily penetrated the cyst wall and revealed a cluster of at least 4 large vesicles (Fig. 2).

Cyst B was ovoid and slightly smaller than most cysts of Type A ( 7 to $12 \mu \mathrm{m}$ ). The surface of the cell appeared irregular under light microscopy (Fig. 2). The cell wall was not as thick as in Cyst A, and did not stain with proflavine. The cell wall of Cyst B did stain bluishwhite with calcofluor (Fig. 2). Similar to Cyst A, these stains suggest that the cell wall of Cyst B is composed of cellulose, but not protein. SYTOX and CMFDA did not stain Cyst B indicating an intact cell that is not active. Cyst $B$ was resistant to direct staining by the nucleic acid stains DAPI and SYTO 13. As with Cyst A, the nucleus of Cyst B can be stained through live staining the cysts' precursors (zoospores). The nuclear material was condensed and looked similar to the other stages (Fig. 2). The lipophilic stain, Nile Red, penetrated the wall of Cyst B and revealed a cluster of at least 4 large stained vesicles, as well as a ring of smaller vesicles surrounding the unstained nucleus (Fig. 2).

\section{Dynamics observed in laboratory experiments}

The results of the laboratory experiment are shown in Fig. 3. In the control (unfed) treatment, 'Light' exposed zoospores persisted with only minor losses in abundance for the first $5 \mathrm{~d}$. In contrast, the 'Dark' exposed zoospores appeared to decrease almost immediately. By Day 5, zoospore numbers in the 'Dark' treatment had decreased to approximately half the cell concentration of the 'Light' treated control flask on the same day. After Day 5, zoospore numbers in the 2 irradiance treatments continued to decrease, eventually converging on a similar concentration $\left(\sim 150\right.$ cells ml$\left.^{-1}\right)$ by Day 13.

The zoospores observed in the fed treatments actively grazed the algal prey species, Storeatula major. In fed treatments, zoospores grazed the algal prey to low or undetectable concentrations by the first day. While actively feeding on prey, zoospores contained visible cryptophyte inclusions. By Day 3, all prey concentrations were below detectable limits and cryptophyte inclusions in the zoospores were no longer visible. Still, zoospores persisted for at least $2 \mathrm{~d}$ more before decreasing significantly in abundance. Despite the higher growth rate and higher maximum abundance in all fed, 'Light' treatments, zoospore concentrations eventually converged to a similar concentra-

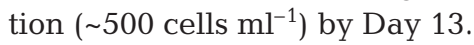

Initial concentrations of Cyst $\mathrm{A}$ and Cyst B in all

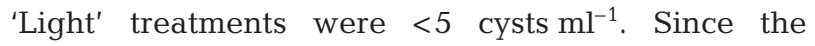
'Dark' treatments were run $7 \mathrm{~d}$ after the 'Light' experiments, Cyst A concentrations accumulated in the stock such that the initial concentrations of Cyst A were approximately 10 cells ml$^{-1}$ (Fig. 3). Initial differences in Cyst B concentrations between 'Light' and 'Dark' treatments were not as pronounced (Fig. 3). Throughout the experiment, no evidence of 'empty' cysts or excystment debris was observed in any treatment combination. Therefore, it is believed that this initial difference in concentration did not affect the laboratory dynamics.

In the unfed treatment, Cyst A and Cyst B (Fig. 3) concentrations did not increase significantly during the experiment ( $p>0.05$; Kruskal-Wallis ranked test). In the 2:1 prey:Pfiesteria treatment, in both the 'Light' and 'Dark' exposed flasks, Cyst A concentration increased until Day 5. After Day 5, Cyst A concentrations leveled and maintained a maximum concentration of 35 to 45 cysts ml $^{-1}$. Cyst B concentrations in the 2:1 prey:Pfiesteria treatments only increased in the 'Dark' exposed flasks after a lag period of $1 \mathrm{~d}$ and saturated by Day 3 at approximately 35 cysts ml$^{-1}$. Cyst A concentrations in the 5:1 prey:Pfiesteria treatment increased up to Day 5. The 5:1 prey:Pfiesteria treatment flasks showed higher variances and more scatter in concentrations than the 2:1 treatments (Fig. 3). Cyst B concentrations in the 5:1 prey:Pfiesteria treatment increased in the 'Dark' exposed flasks and saturated by Day 5 at approximately 25 cysts $\mathrm{ml}^{-1}$.

\section{DISCUSSION}

The number of stages observed in the NON-IND strain of Pfiesteria piscicida was much less than the number of observed forms in TOX-A and TOX-B functional types (Burkholder \& Glasgow 1997a, Burkholder et al. 2001). This difference may reflect a physiological difference between toxic and NON-IND functional types. Alternatively, the differences observed are attributable to the types and quantity of environmental stimuli tested.

Zoospore morphology was similar to that described by Steidinger et al. (1996). Zoospore dynamics in the laboratory experiments appeared to be consistent with kleptochloroplastidic mixotrophy as described by Lewitus et al. (1999). The 2 cysts found in this Pfiesteria piscicida strain appear morphologically different and are induced under different environmental conditions. Cyst A has a thick, resistant cell wall that may aid resistance to adverse environmental conditions. Cyst A appeared to form from actively feeding 
Zoospores

a)

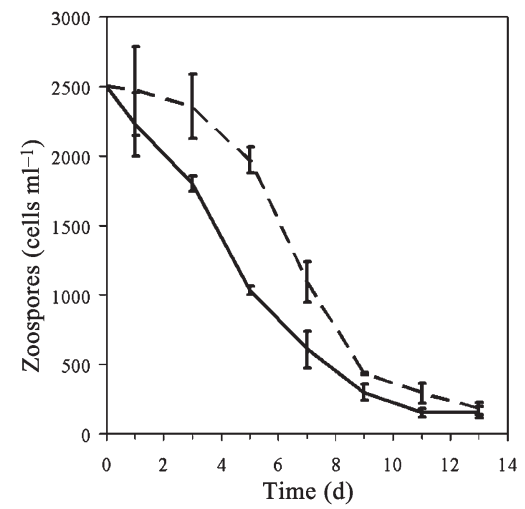

b)

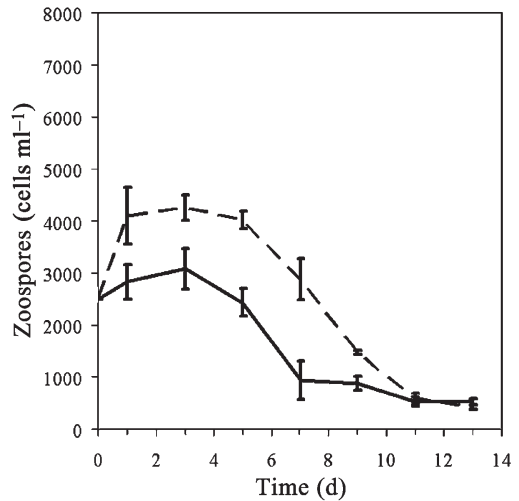

c)

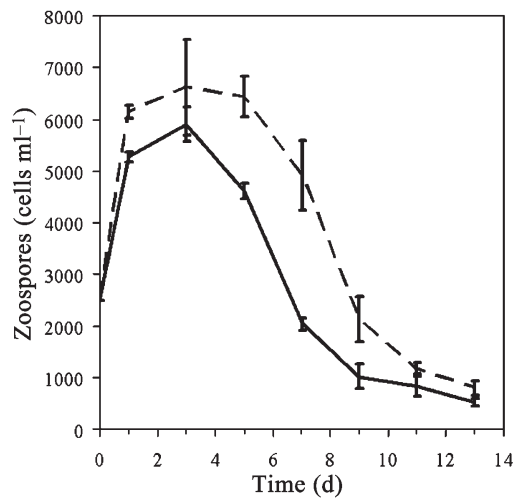

Cyst A
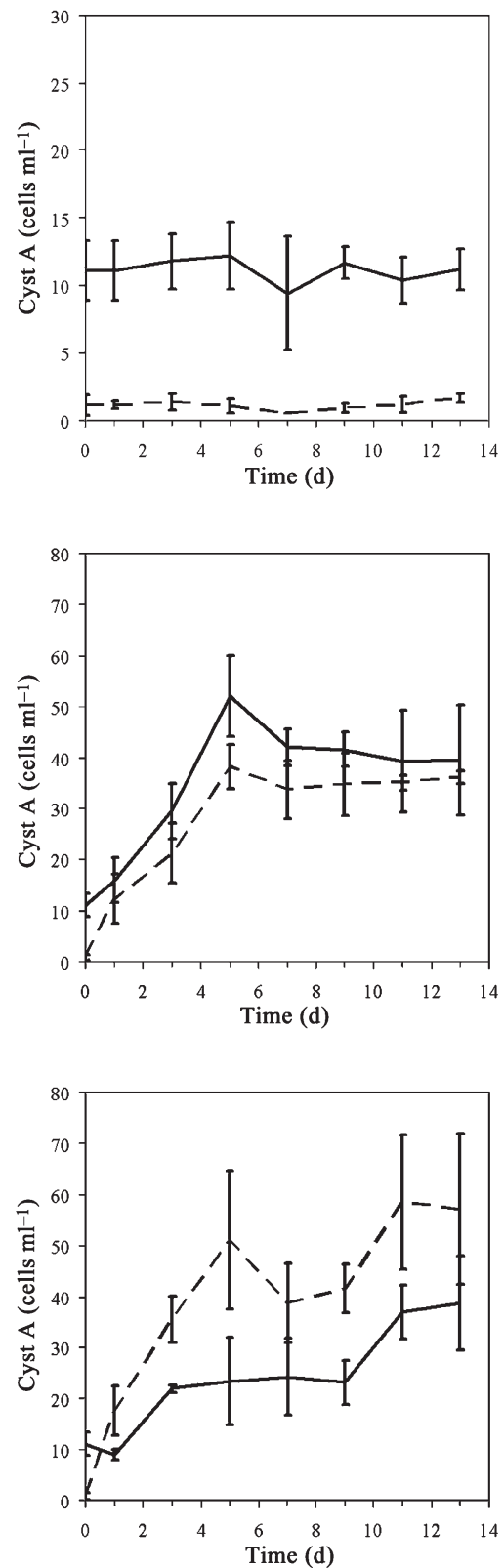

Cyst B
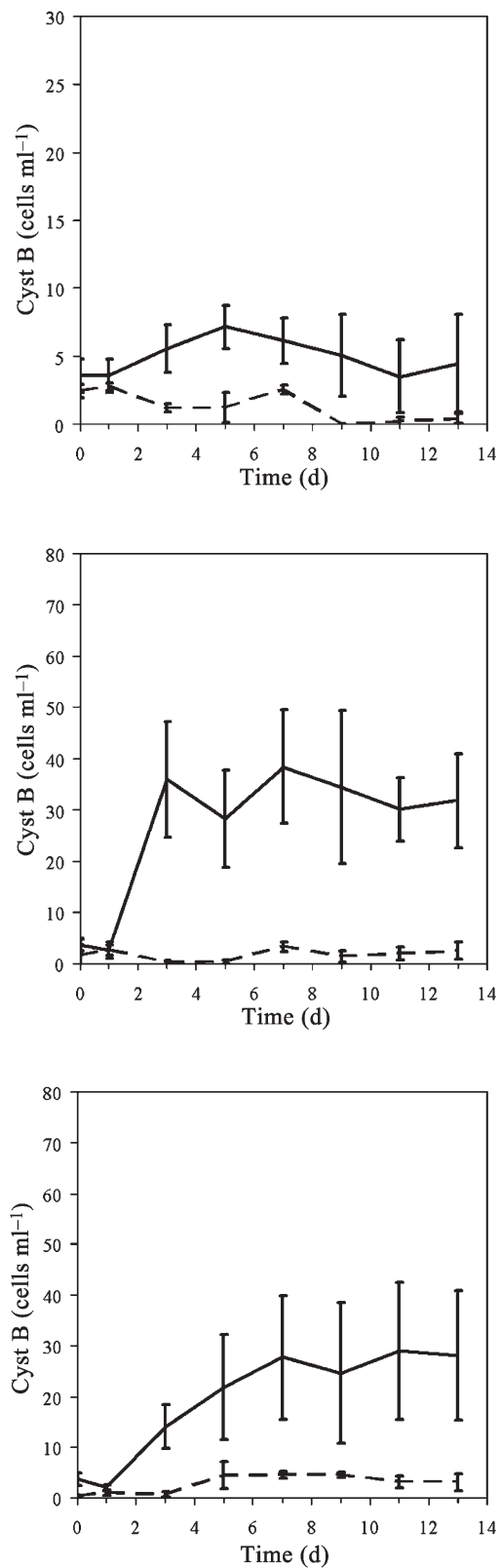

Fig. 3. Pfiesteria piscicida. Numbers of cells $\mathrm{ml}^{-1}$ (means $\pm \mathrm{SD}$ ). Columns represent concentrations of the 3 life stages: zoospores, Cyst A, and Cyst B. Rows represent different prey concentration treatments: (a) unfed control, (b) 2:1 prey:Pfiesteria ratio, (c) 5:1 prey:Pfiesteria ratio. For each graph, comparisons are made between the 'Light' treatments (dashed line) and 'Dark' treatments (solid line). Means are plotted with error bars representing $\pm 1 \mathrm{SD}$

or recently fed zoospores, regardless of light intensity (Fig. 3). In contrast to Cyst A, Cyst B has a thinner cell wall. This suggests that it may be more temporary than Cyst A, possibly allowing populations to rapidly respond to algal stimuli. In the laboratory experiments, Cyst B formed from recently fed zoospores and only when exposed to complete darkness (Fig. 3).
In the laboratory experiments, light-treated starved zoospores appeared to survive with minimal losses for a few days before dramatically losing numbers. In contrast, the dark-treated starved zoospores declined immediately. These dynamics are consistent with observations of kleptochloroplastidic mixotrophs (Stoecker et al. 1988, Skovgaard 1998, Lewitus et al. 1999, Jakobsen et al. 2000). However, because zoo- 
spore concentrations did not increase during this period, this suggests that the energy obtained from stolen chloroplasts may only cover respiration and maintenance costs. As an alternative to mixotrophy, the zoospores could also be surviving by slowly digesting food vacuoles without using them photosynthetically.

The observation that zoospore concentrations in all treatments eventually converged by Day 13 (Fig. 3) is puzzling because of the differences in initial prey concentrations and light intensity imposed by the treatments. A possible explanation is that the zoospores are surviving on an alternative food source at these low concentrations. This alternative food source may be detritus and/or heterotrophic bacteria that are sometimes abundant in old cultures. If the remaining zoospores in the culture experiments grazed on detritus and/or bacteria, the quality of this food source (as compared to algal prey) may not be enough to maintain concentrations above the observed 500 cells ml-1. Although in some cultures zoospores were observed consuming detritus when algal prey was depleted, exact rates and the relative importance of this food source were not quantified.

The appearance of Cyst A is similar to the sexual cyst described in Burkholder \& Glasgow (1997a). The formation of Cyst A from feeding or recently fed zoospores is consistent with the formation of sexual cysts from toxic zoospores (Burkholder and Glasgow 1997a; Fig. 2). Assuming Cyst $\mathrm{A}$ is derived from a diploid planozygote, it is possible that these cysts may also be diploid. However, ploidy of a sexual cyst is dependent on whether meiosis occurs prior to encystment or after excystment (Coats et al. 1984, Pfiester \& Anderson 1987). The ploidy of a cell and its position in mitosis or meiosis may be apparent based on the size or brightness of stained nuclear material. Diploid cells, and cells in $\mathrm{S}$ phase, should have larger and brighter stained nuclei. From these experiments, there is no visible evidence of differences in the size or brightness of SYTO 13 stained nuclear material among stages that would suggest diploidy (Fig. 2).

The thickness of Cyst A's cell wall might aid in the persistence and long-term survival of this cyst in sediments. However, if these cysts have a dormancy of several months, they may require energy stores to cover respiration and maintenance. Many dinoflagellate cysts contain high concentrations of lipid droplets (Pfiester \& Anderson 1987) which could provide the energy needed for cysts to survive long periods of time. From Nile Red staining, Cyst A appeared to have a cluster of at least 4 large vesicles within the cell (Fig. 2). It is possible that these vesicles are lipid droplets. However, both the zoospore and Cyst B stages also had a cluster of similar vesicles within the cell
(Fig. 2). Since they are found in all life stages, it is unlikely they are storage vesicles for dormancy. Alternatively, they may be Golgi bodies, smooth endoplasmic reticulum (ER), or lysosomes.

Some cysts can also have red accumulation bodies called 'eye spots' (Heiskanen 1993, Montresor 1995). Cyst A often contained a large reddish vesicle. However, from its red-orange autofluorescence, the vesicle found in Cyst A may be a food vacuole containing cryptophyte prey. CMFDA did not stain Cyst A, but did appear to stain the red vesicle. This suggests that the cyst is permeable to CMFDA, and that cyst activity is only detectable within the red vesicle. If the red vesicle is a food vacuole, then activity within the vacuole could signify digestion. Alternatively, for a kleptoplastidic organism, the maintenance of activity within a food vacuole could represent photosynthetic activity of that cyst.

Cyst B is similar in morphology to the asexual cyst described in Burkholder \& Glasgow (1997a). In contrast to Cyst A, Cyst B may be a short-term resting stage that forms in response to unfavorable conditions. Direct evidence for this hypothesis could only be obtained with excystment experiments. Temporary cysts of other dinoflagellates often form in post-exponential and stationary phases of cultures when conditions become unfavorable for growth (Jensen \& Moestrup 1997). In these laboratory experiments, Cyst B concentrations only began to increase after the prey was depleted (Day 1; Fig. 3). Furthermore, Cyst B only formed in complete darkness, presumably when zoospores could not be mixotrophic. The thin cell wall also suggests that Cyst B is a short-term resting stage. In some dinoflagellates, short-term cysts have a pellicle wall with short projections (Heiskanen 1993). Under light microscopy, the cell wall of Cyst B appears irregular, and may be covered with short projections (Fig. 2).

The fluorescent stain results suggest that Cyst B is a morphotype that comprises characteristics from both zoospore and Cyst A stages. When stained with Nile Red, Cyst B contains the same cluster of large vesicles found in all stages (Fig. 2). In addition, Cyst B and the zoospore stage contain a ring of smaller vesicles surrounding the nucleus. These smaller vesicles may be organelles associated with the nucleus, such as rough ER. The similarity between Nile Red staining of the zoospore and Cyst B suggests that Cyst B is closer in morphology to the zoospore stage than Cyst A. An internal morphology similar to the vegetative cell could affect how rapidly Cyst B responds to stimuli. However, the cyst's activity as determined by CMFDA staining is minimal (Figure 2). Furthermore, it appears that the cell wall is also resistant to the nucleic acid stains DAPI and SYTO 13. 


\section{CONCLUSIONS}

The dynamics in the laboratory experiments are consistent with the observations of Lewitus et al. (1999), which suggest this organism is mixotrophic. After prey was depleted, light-treated zoospores survived longer than dark-treated zoospores. The laboratory results show that certain combinations of light intensity and prey concentrations affected zoospore growth and encystment, possibly by influencing the zoospore's mixotrophic ability. The formation of Cyst B in response to darkness suggests that adverse environmental conditions can induce encystment. In contrast, the formation of Cyst A while actively feeding, regardless of light intensity, suggests this cyst is formed in optimal growth conditions, or just as conditions become unfavorable. Formation of Cyst A in these conditions is consistent with toxic functional types, which undergo a sexual cycle while feeding on fish prey (Burkholder \& Glasgow 1997b). However, there is no direct evidence for this linkage. Further research on the sexual cycle and ploidy of these life stages is necessary to determine the relationship between Cyst A and the sexual cycle.

The ecological role of Cyst $\mathrm{A}$, and possibly its role in a sexual cycle, may be in the dispersal and genetic mixing of populations. With its resistant cell wall, this cyst could potentially survive for long periods and through adverse environmental conditions. If dispersed by currents to a different habitat, these cysts may become seed for new populations or genetically mix with existing populations. Ecologically, Cyst B may form when zoospore populations encounter lightlimiting regions such as humic estuaries and tributaries. Alternatively, encystment may occur in deep water when populations are transported below the euphotic depth or during subpycnocline transport. If this is the case, there should be a higher concentration of Cyst B in sediments of humic tributaries such as the Pocomoke River, Maryland, or in deep channels when light penetration is minimal. To our knowledge, no published studies have looked at the spatial distribution of these Pfiesteria piscicida cysts in sediments.

The abundance of cysts in laboratory experiments reflects very low encystment rates. Unfortunately, determining exact encystment rates from these laboratory experiments is confounded by zoospore growth, prey growth and mixotrophic ability. Anderson et al. (2003, this issue) apply a numerical model to the laboratory experiments to 'back out' specific growth and encystment parameters. These results show that encystment rates to either stage in this non-inducible strain are lower than maximum encystment rates for other dinoflagellates (Anderson et al. 1985, Agbeti \& Smol 1995). If these rates apply to natural populations, then in short timescales these cysts will not play a major role in bloom dynamics. However, if given enough time for excystment, both cyst stages may play a major role in initiating blooms, especially in regions where currents can accumulate cysts to form 'seed beds'.

Differences between toxic and NON-IND functional types of Pfiesteria piscicida have been identified and need to be considered in order to understand the complete ecological role of the $P$. piscicida species complex. For example, Stoecker et al. (2000) found that grazing rates on Pfiesteria are affected by the toxic history of the strain. Furthermore, unpublished observations comparing recently toxic and non-inducible encystment suggest that recently toxic forms behave differently, encyst at higher rates, and form cyst aggregates (J. T. Anderson unpubl.). These observations suggest that the toxic history of strains needs to be quantified and comparative studies need to examine the extent to which the ability to become toxic is related to life cycle dynamics.

Acknowledgements. This research was conducted as part of a dissertation and was funded by a Horn Point Laboratory Small Grant and Fellowship. Additional funding was provided by NOAA and ECOHAB. We thank Dr. JoAnn M. Burkholder and Dr. Wayne Coats for their helpful comments on the life stages encountered. We also thank Dr. Paul del Giorgio, Jason Adolf, Matthew Johnson, and Daniel Gustafson for their input on dinoflagellate mixotrophy and fluorescent staining.

\section{LITERATURE CITED}

Agbeti MD, Smol JP (1995) Chrysophyte population and encystment patterns in two Canadian lakes. J Phycol 31: $70-78$

Anderson DM, Coats DW, Tyler MA (1985) Encystment of the dinoflagellate Gyrodinium uncatenum: temperature and nutrient effects. J Phycol 21(2):200-206

Anderson JT, Hood RR, Zhang X (2003) Quantification of Pfiesteria piscicida growth and encystment parameters using a numerical model. Mar Ecol Prog Ser 246:105-113

Blackburn SI, Hallegraeff GM, Bolch CJ (1989) Vegetative reproduction and sexual life cycle of the toxic dinoflagellate Gymnodinium catenatum from Tasmania, Australia. J Phycol 25(3):577-590

Blanco J (1995) Cyst production in four species of neritic dinoflagellates. J Plankton Res 17(1):165-182

Bowers HA, Tengs T, Glasgow HB, Burkholder JM, Rublee P, Oldach D (2000) Development of real-time PCR assays for rapid detection of Pfiesteria piscicida and related dinoflagellates. Appl Environ Microbiol 66(11):4641-4648

Burkholder JM, Glasgow HB (1995) Interactions of a toxic estuarine dinoflagellate with microbial predators and prey. Arch Protistenkd 145:177-188

Burkholder JM, Glasgow HB (1997a) Pfiesteria piscicida and other Pfiesteria-like dinoflagellates: behavior, impacts, and environmental controls. Limnol Oceanogr 42(5):1052-1075

Burkholder JM, Glasgow HB (1997b) Trophic controls on 
stage transformations of a toxic ambush-predator dinoflagellate. J Eukaryot Microbiol 44(3):200-205

Burkholder JM, Glasgow HB, Hobbs CH (1995) Fish kills linked to a toxic ambush-predator dinoflagellate: distribution and environmental conditions. Mar Ecol Prog Ser 124: 43-61

Burkholder JM, Glasgow HB, Deamer-Melia NJ, Springer J, Parrow MW, Zhang C, Cancellieri PJ (2001) Species of the toxic Pfiesteria complex and the importance of functional type in data interpretation. Environ Health Perspect 109: 667-686

Coats DW, Tyler MA, Anderson DM (1984) Sexual processes in the life cycle of Gyrodinium uncatenum (Dinophyceae): a morphogenetic overview. J Phycol 20(3):351-361

del Giorgio PA, Bird DF, Prairie YT, Planas D (1996) Flow cytometric determination of bacterial abundance in lake plankton with the green nucleic acid stain SYTO 13. Limnol Oceanogr 41(4):783-789

Doucette GJ, Cembella AD, Boyer GL (1989) Cyst formation in the red tide dinoflagellate Alexandrium tamarense (Dinophyceae): effects of iron stress. J Phycol 25(4):721-731

Fritz L, Triemer RE (1985) A rapid simple technique utilizing calcofluor white M2R for the visualization of dinoflagellate thecal plates. J Phycol 21(4):662-664

Greenspan P, Mayer EP, Fowler SD (1985) Nile Red: a selective fluorescent stain for intracellular lipid droplets. J Cell Biol 100:965-973

Haas LW (1982) Improved epifluorescence microscopy for observing planktonic micro-organisms. Ann Inst Oceanogr 58(Suppl):261-266

Hardeland R (1994) Induction of cyt formation by low temperature in the dinoflagellate Gonyaulax polyedra Stein: dependence on circadian phase and requirement of light. Experientia 50(1):60-62

Heiskanen AS (1993) Mass encystment and sinking of dinoflagellates during a spring bloom. Mar Biol 116(1):161-167

Jakobsen HH, Hansen PJ, Larsen J (2000) Growth and grazing responses of two chloroplast-retaining dinoflagellates: effect of irradiance and prey species. Mar Ecol Prog Ser 201:121-128

Jensen MØ, Moestrup Ø (1997) Autecology of the toxic dinoflagellate Alexandrium ostenfeldii: life history and growth at different temperatures and salinities. Eur J Phycol 32(1): 9-18

Jochem FJ (1999) Dark survival strategies in marine phytoplankton assessed by cytometric measurement of metabolic activity with fluorescein diacetate. Mar Biol 135(4): $721-728$

Editorial responsibility: Otto Kinne (Editor),

Oldendorf/Luhe, Germany
Kremp A, Heiskanen AS (1999) Sexuality and cyst formation of the spring-bloom dinoflagellate Scrippsiella hangoei in the coastal northern Baltic Sea. Mar Biol 134:771-777

Lebaron P, Catala P, Parthuisot N (1998) Effectiveness of SYTOX green stain for bacterial viability assessment. Appl Environ Microbiol 64(7):2697-2700

Lewitus AJ, Glasgow HB, Burkholder JM (1999) Kleptoplastidy in the toxic dinoflagellate Pfiesteria piscicida (Dinophyceae). J Phycol 35:303-312

Mallin MA, Burkholder JM, Larsen LM, Glasgow HB (1995) Response of two zooplankton grazers to an ichthyotoxic estuarine dinoflagellate. J Plankton Res 17(2):351-363

Montresor M (1995) The life history of Alexandrium pseudogonyaulax (Gonyaulacales, Dinophyceae). Phycologia 34(6): $444-448$

Pfiester LA, Anderson DM (1987) Dinoflagellate Reproduction. In: Taylor FJR (ed) The biology of dinoflagellates. Blackwell Scientific Publications, Boston, p 611-648

Porter KG, Feig YS (1980) The use of DAPI for identifying and counting aquatic microflora. Limnol Oceanogr 25:943-948

Rengefors K, Karlsson I, Hansson LA (1998) Algal cyst dormancy: a temporal escape from herbivory. Proc $\mathrm{R}$ Soc Lond Ser B 265(1403):1353-1358

Sanderson BL, Frost TM (1996) Regulation of dinoflagellate populations: relative importance of grazing, resource limitation, and recruitment from sediments. Can J Fish Aquat Sci 53:1409-1417

Sgrosso S, Esposito F, Montresor M (2001) Temperature and daylength regulate encystment in calcareous cyst-forming dinoflagellates. Mar Ecol Prog Ser 211:77-87

Skovgaard A (1998) Role of chloroplast retention in a marine dinoflagellate. Aquat Microb Ecol 15:293-301

Steidinger KA, Burkholder JM, Glasgow HB, Hobbs CW, Garrett JK, Truby EW, Noga EJ, Smith SA (1996) Pfiesteria piscicida gen. et sp. nov. (Pfiesteriaceae fam. nov.), a new toxic dinoflagellate with a complex life cycle and behavior. J Phycol 32(1):157-164

Stoecker DK (1999) Mixotrophy among dinoflagellates. J Eukaryot Microbiol 46(4):397-401

Stoecker DK, Silver MW, Michaels AE, Davis LH (1988) Obligate mixotrophy in Laboea strobila, a ciliate which retains chloroplasts. Mar Biol 99:415-423

Stoecker DK, Stevens K, Gustafson DE (2000) Grazing on Pfiesteria piscicida by microzooplankton. Aquat Microb Ecol 22:261-270

Tyler MA, Coats DW, Anderson DM (1982) Encystment in a dynamic environment: deposition of dinoflagellate cysts by a frontal convergence. Mar Ecol Prog Ser 7(2):163-178

Submitted: November 11, 2001; Accepted: July 18, 2002

Proofs received from author(s): December 19, 2002 